Who Knows, Who Cares?

\title{
Dementia knowledge among nurses, care workers, and family members of people living with dementia
}

Andrew Robinson, Claire Eccleston, Michael Annear, Kate-Ellen Elliott, Sharon Andrews, Christine Stirling, Michael Ashby, Catherine Donohue, Susan Banks, Christine Toye, and Fran Mclnerney

\begin{abstract}
A Robinson (corresponding author): School of Health Sciences and Wicking Dementia Research and Education Centre, Faculty of Health, University of Tasmania, Private Bag 143, Hobart TAS 7001, Australia; Andrew.Robinson@utas.edu.au

C Eccleston, M Annear, KE Elliott, S Andrews, S Banks: Wicking Dementia Research and Education Centre, Faculty of Health, University of Tasmania, Hobart, Tasmania, Australia; C Stirling: School of Health Sciences, University of Tasmania, Hobart, Tasmania, Australia; M Ashby: Faculty of Health, University of Tasmania, Hobart, Tasmania, Australia; and Royal Hobart Hospital (THO-South), Hobart, Tasmania, Australia; C Donohue: Australian Catholic University/Mercy Health, Melbourne, Fitzroy, Victoria, Australia; C Toye: Faculty of Health Sciences, Curtin University, Perth, Australia; F Mclnerney: Australian Catholic University/Mercy Health, Melbourne, Victoria, Australia
\end{abstract}

Keywords: dementia knowledge, palliative care, nursing, care workers, family

\begin{abstract}
The number of people with dementia is increasing rapidly worldwide. Commensurate with population ageing, the use of nursing homes in Australia (known as residential aged care facilities) for individuals with dementia is growing. As a terminal condition, dementia is best managed by instituting a palliative approach to care. A good knowledge of dementia, including its progression and management, among staff and families of people living with dementia is essential for clear decision making and the provision of appropriate care. Yet there is limited information regarding relative levels of dementia knowledge. This paper reports the results of a study that assessed dementia knowledge among these two cohorts using the Dementia Knowledge Assessment Tool; the study surveyed 279 staff members and 164 family members of residents with dementia. Dementia knowledge deficits were evident in both cohorts across a range of areas. It is critical that dementia knowledge deficits are identified and addressed in order to support evidencebased dementia care.
\end{abstract}

Résumé / Le nombre de personnes atteintes de démence augmente rapidement à travers le monde. Ainsi on remarque en Australie une augmentation du nombre de ces malades admis dans les institutions de soins de longue durée. La démence étant une maladie terminale il appert que l'approche palliative est la meilleure forme de soins. Cependant, il est essentiel que le personnel soignant autant que les familles aient une bonne connaissance de la maladie, de ses symptomes, de la façon de traiter les maladies, et des décisions à prendre. Or, on en sait très peu quant au niveau de connaissances de ces deux groupes de personnes sur le sujet. Cet article porte sur les résultats d'une étude qui tentait d'évaluer le niveau de connaissances de 279 membres du personnel et de 164 membres des familles à l'aide de l'Échelle d'évaluation des connaissances sur la démence. Le peu de connaissances était évident chez les deux cohortes et ce, sur un bon nombre de points. Il est donc de la plus haute importance que l'on identifie spécifiquement ces points et qu'on améliore la qualité des soins chez les personnes démentes en se basant sur des données probantes.

\section{INTRODUCTION}

Dementia is a condition primarily associated with old age. Australia, like other countries around the world that are experiencing increasing population longevity (1), expects its number of people living with dementia to more than triple by mid-century (2). Despite increases in government funding for home care support (3), the use of residential aged care facilities (RACFs, elsewhere known as nursing homes) for individuals with dementia is growing, accompanied by an upward shift in the age of admission and rising dependency levels (4). Demographic projections indicate that this scenario of increased demand and growing burden of dementia care need will cause government expenditures on aged care to more than double by the middle of this century (5).

Dementia is progressive, and it is associated with significant morbidity and mortality (6). Consequently, it is argued that people with dementia would benefit from a palliative approach to their care $(7,8)$; this would involve the families of persons living with advanced dementia and healthcare staff collaborating in making decisions 
affecting their care. The ongoing cognitive decline associated with dementia raises particular challenges for care planning and highlights the important role that the families of affected individuals play in the "progressive surrogacy" (9) that is required as the condition advances.

Care staff and families of people experiencing dementia must have knowledge of dementia if they are to engage in clear decision making and offer appropriate ongoing care (10). Yet research has demonstrated that despite its life-limiting nature, 40 percent of people with advanced dementia who reside in RACFs are likely to be subjected to burdensome and inappropriate interventions (6). The failure of care staff and family members to understand the dementia trajectory may have adverse effects on the development of informed advance care plans and contribute to inadequate symptom management (11), overuse of treatments (12), and invasive and futile tests (13).

The consequences of inconsistent or limited knowledge of dementia among care staff and families of people living with dementia are not well understood, and few studies have made comparisons between these two groups. It is the latter gap that this paper endeavours to address (14). Ideally, both groups would possess a high level of dementia knowledge and a capacity to collaborate on a palliative approach to care (7). A palliative approach aims to improve the level of comfort and function (7), and it has been advocated as appropriate for people with dementia (15). Such an approach entails family caregivers acting as central stakeholders in the decision-making process when a person with dementia is no longer able to participate meaningfully in discussions about his or her treatment and care (7).

Before such outcomes can be achieved, however, we must assess the current dementia knowledge of these groups. Studies have examined knowledge among individuals who provide regular care for people with dementia, undertaking research involving RACF staff who report moderate levels of dementia knowledge but who lack confidence in dealing with affected residents $(16,17)$. Specific knowledge discrepancies have been identified in relation to risk factors and to the course of the disease $(16,17)$. Comparatively few researchers have explored dementia knowledge among family carers; three studies conducted in the United Kingdom reported large discrepancies in dementia knowledge among informal carers (18-20).

Gaining an overview of how both formal and informal carers understand dementia is an essential part of evidence-based best practice (7). The aim of this study was to explore the dementia knowledge of formal and family carers of people with dementia living in RACFs. This paper reports on the results of surveys undertaken in three Australian states to assess such knowledge.

\section{METHODS}

\section{Procedure}

The study employed a multi-site, single-timepoint design to survey nurses and care workers employed in RACFs and family members of RACF residents with dementia to ascertain their knowledge of dementia. The data were collected in the course of two projects conducted across three Australian states. Other aspects of these projects were reported elsewhere $(21,22)$. Approval was granted by the human research ethics committees in each of the Australian states.

\section{Participants}

Purposive samples were comprised of RACF staff $(\mathrm{n}=279)$ - including registered nurses (RNs), enrolled nurses (ENs), and care workers (CWs) and of family members of residents with moderate-to-severe dementia $(n=164)$. Samples were recruited in the first project from four RACFs in Tasmania and Victoria (two in each state), and in the second project from four RACFs in Western Australia (22).

Staff members were invited to participate by a researcher who went to the facility during a shift change in order to maximize staff availability. At this time, those staff members who consented to participate completed a supervised, self-administered measure of their dementia knowledge - the Dementia Knowledge Assessment Tool version 2 (DKAT 2) - and then answered a number of demographic and occupational questions. In all, 59 percent of the staff members were surveyed. The reasons given for not participating were unavailability due to leave, working night or weekend shifts, or direct engagement in resident care.

Residents were deemed to have moderate or severe dementia if their records indicated suspected or diagnosed dementia and they met criteria for moderate or severe impairment by scoring between 10 and 21 on the Cognitive Decline subscale of the Psychogeriatric Assessment Scales (23), which is consistent with the categories of moderately severe, severe, and very severe cognitive decline on the Global Deterioration Scale (24). Family members of residents with dementia who met these inclusion criteria were identified by facility staff and invited to participate by the researchers via individual letters mailed from the 
RACF (because they attended the RACF only intermittently). They returned their completed demographic and DKAT 2 forms by mail, with a 58 percent response rate.

\section{Measures}

The DKAT 2 tool (22), used to measure the dementia knowledge of RACF staff and family members of residents with moderate-to-severe dementia, was designed to assess foundationlevel knowledge of dementia in both these carer groups. It has met criteria for adequate internal consistency reliability estimates (Cronbach's alpha $=0.79$, both groups), and it has established content validity (22). The tool has 21 items (7 reverse scored) (see Table 1 for the full list of items).

Response options are "agree," "disagree," or "don't know," collapsed to "correct" or "incorrect" ("don't know" deemed "incorrect"). Scores range from 0 to 21 , with higher scores indicating greater dementia knowledge.

\section{Table 1 / Full List of Dementia Knowledge} Assessment Tool Version 2 Items

1. Dementia occurs because of changes in the brain.

2. Brain changes causing dementia are often progressive.

3. Alzheimer's disease is the main cause of dementia.

4. Blood vessel disease can also cause dementia.

5. Confusion in an older person is almost always due to dementia.

6. Only older adults develop dementia.

7. Knowing the likely cause of dementia can help to predict its progression.

8. Incontinence always occurs in the early stages of dementia.

9. Dementia is likely to limit life expectancy.

10. When a person has late-stage dementia, families can help others to understand that person's needs.

11. People who have dementia may develop problems with visual perception (understanding or recognizing what they see).

12. Sudden increases in confusion are characteristic in dementia.

13. Uncharacteristic distressing behaviours may occur in people who have dementia (e.g., aggressive behaviour in a gentle person).

14. Difficulty swallowing occurs in late-stage dementia.

15. Movement (e.g., walking, moving in a bed or chair) is limited in late-stage dementia.

16. Changing the environment (e.g., putting on a $C D$, opening or closing the blinds) will make no difference to a person who has dementia.

17. When a person who has dementia is distressed, it may help to talk to them about their feelings.

18. It is important to always correct a person who has dementia when they are confused.

19. A person who has dementia can often be supported to make choices (e.g., what clothes to wear).

20. It is impossible to tell if a person who is in the later stages of dementia is in pain.

21. Exercise can sometimes be of benefit to people who have dementia.
Staff members were also asked to give their age and reply to occupational questions. These questions covered their role (for example, RN, EN, or $\mathrm{CW}$ ), the number of years they had been in their current role, and the number of years they had been working in aged care. Family members were asked to report their age and their relationship to the person with dementia.

\section{Data Analysis}

Data were entered into SPSS 20.0 (IBM Corp., 2011). A sum of item responses generated a DKAT 2 score out of 21, and internal consistency of the DKAT 2 tool was examined using Cronbach's alpha. Descriptive statistics were generated for scores, age, and occupational items.

DKAT 2 scores were compared between the two groups - nursing staff and care workers (RNs, ENs, and CWs), and family members of residents with dementia - using a Welch's ANOVA test, which is robust to heterogeneous variance (25) (see variances in Table 2). The percentages of respondents answering individual DKAT 2 items correctly were also examined to determine key deficiencies and strengths in the respondents' dementia knowledge. The percentage-correct scores were examined using a chi-squared test for each item to determine whether there were significant differences between the two respondent groups. Bonferroni correction adjusted for the number of pairwise comparisons (26).

In order to better understand aspects that could be related to the dementia knowledge of RACF staff, we examined the correlations between DKAT 2 scores and the number of years in the current role and the number of years in aged care. Spearman's rank-order correlation was used due to the non-normal distributions of data for the examined variables according to the criteria set out by Onwuegbuzie and Daniel (27).

\section{RESULTS}

A total of 284 respondents participated in the Tasmania/Victoria project: 174 nurses and care workers and 110 family members of residents with moderate-to-severe dementia. The Western Australia project had a total of 91 respondents: 58 nurses and care workers and 33 family members. The modal age range for staff was 46 to 55 years, and there were few young staff members ( 6.8 percent under age 25), consistent with aged care workforce figures for Australia nationally (28). The most common age range for family members (36 percent) was 56 to 65 years, and 58 percent were children of the person with dementia (16 percent were spouses, and 26 percent were grandchildren, in-laws, friends, and others). Staff 
Table 2 / Dementia Knowledge Assessment Tool Version 2 Scores of Nursing and Care Staff and Family Members of Residents with Moderate-to-Severe Dementia

\begin{tabular}{l|c|c|c|c}
\hline & $\begin{array}{c}\text { Mean } \\
( \pm \text { SD })\end{array}$ & Median & Range & Variance \\
\hline $\begin{array}{l}\text { Registered nurses } \\
(\mathrm{n}=35)\end{array}$ & $16.8( \pm 2.5)$ & 17.0 & $11-21$ & 6.2 \\
\hline $\begin{array}{l}\text { Enrolled nurses } \\
(\mathrm{n}=36)\end{array}$ & $16.3( \pm 2.5)$ & 16.5 & $11-21$ & 6.1 \\
\hline $\begin{array}{l}\text { Care workers } \\
(\mathrm{n}=161)\end{array}$ & $14.9( \pm 3.1)$ & 15.0 & $3-21$ & 9.7 \\
\hline $\begin{array}{l}\text { Family carers } \\
(\mathrm{n}=143)\end{array}$ & $13.2( \pm 3.8)$ & 13.0 & $3-21$ & 14.2 \\
\hline
\end{tabular}

Figure 1 / DKAT 2 (Dementia Knowledge Assessment Tool Version 2) scores of Registered Nurses (RNs), Enrolled Nurses (ENs), Care Workers (CWs), and Family Members of Residents with Moderate-to-Severe Dementia

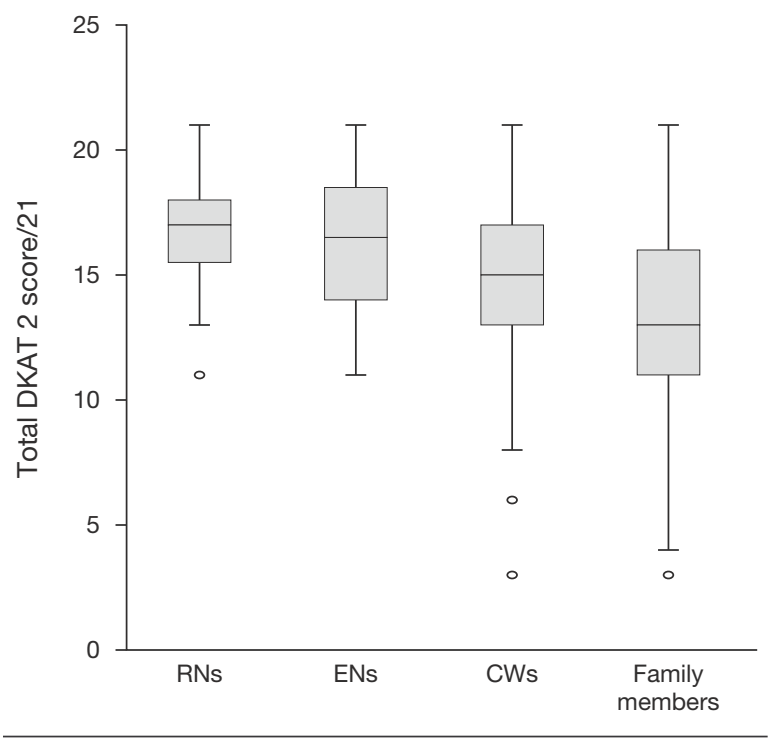

members had been in their current work role for a median of 4 years (range: 0 to 35 years), again similar to national figures, as reported by King et al. (28). However, staff had been in aged care for a median of 7 years (range: 0.5 to 41 years), whereas nationally more than 56 percent of the staff group made up of RNs, ENs, and personal care assistants have worked for more than 10 years (28).

Cronbach's alpha for the 21 DKAT 2 items $(\alpha=.73, \mathrm{n}=375)$ indicated an acceptable internal consistency for the scale (29). Mean DKAT 2 scores were significantly higher for nurses and care workers than for the family members of residents with moderate-to-severe dementia (Table 2); (Welch's F $(1,259.96)=38.49, \mathrm{p}<.001)$.
Within the nurse and care worker group, nursing staff scores exhibited lower variance than those of care workers (Table 2). Indeed, care workers had the same range of scores as family members, although this was influenced by one outlying (low) score (Figure 1), and the interquartile range was not as large as that of family members' scores.

A high total score on the DKAT 2 was also positively correlated with the number of years nurses and care workers spent in aged care $\left(\mathrm{r}_{\mathrm{s}}[227]=.27\right.$, $\mathrm{p}<.001$ ), and a weaker relationship was exhibited with the number of years in their current work role $\left(\mathrm{r}_{\mathrm{s}}[221]=.17, \mathrm{p}=.013\right)$.

Several items - typically those interrogating knowledge of the pathophysiology of dementia (items 1, 2, 4, and 6; scores not itemized here), behavioural and psychological symptoms of dementia (items 13, 17, and 18; scores not itemized here), and general decision-making aspects of dementia and dementia care (items 10 and 19; scores not itemized here) - were answered correctly by large proportions (over 85 percent) of all of the groups. However, items identified by members of the research team (AR, FM, CT, and SA) as addressing issues of clinical significance (items 5, 8, 12, 14, 15, 16, and 20) (Table 3) that are implicated in advanced dementia's terminal clinical course (6) were answered incorrectly by many respondents across all groups, or they were answered correctly by a significantly lower proportion of the family member group than of the nurse and care staff group. Furthermore, item 9 (Table 3), which specifically relates to knowledge of dementia's life-limiting course, was also incorrectly answered by many respondents.

\section{DISCUSSION}

This paper rests on three interrelated premises: that dementia is a progressive, irreversible, and life-limiting neurodegenerative disorder; that a palliative approach is an appropriate care framework for those with this condition; and that shared knowledge of the dementia trajectory is a desirable precondition for those engaged in care planning for those with advanced dementia living in RACFs - specifically, nurses and care staff and family members. This third premise - that shared dementia-related knowledge among those who plan related care is desirable - was the immediate imperative for the study reported here.

While gaps in dementia-related knowledge have been identified in families of people with dementia $(19,30)$, the general public $(31,32)$, physicians $(33,34)$, and nurses $(35,36)$, the findings of this study highlight specific dementia knowledge deficits among formal carers and 
Table 3 / Percentage of Each Group (Staff and Family Members) Who Answered Individual Dementia Knowledge Assessment Tool Version 2 Items Correctly

\begin{tabular}{|c|c|c|c|c|c|c|}
\hline No. & Item & $\begin{array}{c}\mathrm{RNs}^{\mathrm{a}} \\
\%\end{array}$ & $\begin{array}{c}\mathrm{ENs}^{\mathrm{b}} \\
\%\end{array}$ & $\begin{array}{c}\mathrm{CWs}^{\mathrm{c}} \\
\%\end{array}$ & $\begin{array}{c}\text { Nursing and } \\
\text { care staff } \\
\text { (grouped) } \\
\%\end{array}$ & $\begin{array}{c}\text { Family } \\
\text { members } \\
\%\end{array}$ \\
\hline 5 & $\begin{array}{l}\text { Confusion in an older person is almost always } \\
\text { due to dementia }(R)^{d} \text {. }\end{array}$ & 90.0 & 88.9 & 71.2 & 76.8 & $59.0^{\mathrm{e}^{\star \star \star}}$ \\
\hline 8 & $\begin{array}{l}\text { Incontinence always occurs in the early stages } \\
\text { of dementia (R). }\end{array}$ & 85.0 & 84.4 & 71.4 & 75.5 & $63.7^{\star *}$ \\
\hline 9 & Dementia is likely to limit life expectancy. & 57.5 & 51.1 & 47.4 & 49.5 & 40.6 \\
\hline 12 & $\begin{array}{l}\text { Sudden increases in confusion are characteristic } \\
\text { of dementia (R). }\end{array}$ & 50.0 & 40.5 & 17.8 & 26.0 & $9.1^{* \star *}$ \\
\hline 14 & Difficulty swallowing occurs in late-stage dementia. & 67.5 & 68.9 & 62.6 & 64.3 & $47.1^{\star \star}$ \\
\hline 15 & Movement...is limited in late-stage dementia. & 67.5 & 64.4 & 69.5 & 68.4 & $55.2^{* *}$ \\
\hline 16 & $\begin{array}{l}\text { Changing the environment... will make no difference } \\
\text { to a person who has dementia (R). }\end{array}$ & 77.5 & 79.5 & 60.2 & 65.8 & $49.0^{\star \star}$ \\
\hline 20 & $\begin{array}{l}\text { It is impossible to tell if a person who is in the later } \\
\text { stages of dementia is in pain }(R) \text {. }\end{array}$ & 70.7 & 71.1 & 62.8 & 65.3 & $33.8^{\star \star \star}$ \\
\hline \multicolumn{7}{|c|}{$\begin{array}{l}\text { a Registered nurses. } \\
\text { " Enrolled nurses. } \\
{ }^{\mathrm{c}} \text { Care workers. } \\
\mathrm{d} \text { Reversed items. } \\
{ }^{\mathrm{e}} \text { Asterisks indicate significant differences between family members and the group comprising nurses and care staff: } \\
{ }^{*}=p<.05,{ }^{* *}=p<.01, \text { and }{ }^{* * *}=p<.001 .\end{array}$} \\
\hline
\end{tabular}

family cohorts. Dementia knowledge in the RACF environment is a critical issue, as over 50 percent of Australian aged care residents can be expected to have some form of dementia (37).

Importantly, our findings highlight problems with dementia knowledge among all levels of aged care staff and residents' family members in two key areas: dementia's life-limiting nature (reflected in item 9, Table 3), and the onset of physical symptoms associated with its progression (items 5, 8, 12,14, 15, 16, and 20). Of particular note is the lack of understanding among approximately 50 percent of aged care staff and 60 percent of family carers that dementia is a terminal illness. This finding has been identified elsewhere $(38,39)$, and it is perhaps not surprising, given the World Health Organization's recent suggestion that the "independent contribution of dementia to mortality is difficult to assess" (40, p. 24). However, this lack of awareness may go some way toward explaining the results of the US study by Mitchell et al. (6), which found that 40 percent of people with dementia resident in RACFs underwent an unnecessary, burdensome intervention - principally, intravenous therapy, tube feeding, and / or hospital and emergency department transfers - in the last three months of their lives. Further supporting the link between knowledge of dementia's terminal trajectory and related care decisions, Mitchell et al.'s (6) work also determined that when the families of people experienc- ing dementia had improved knowledge, the rate of such interventions was significantly reduced.

Other knowledge deficits identified in this study include factors encountered in advanced dementia that indicate and/or contribute to impending mortality - principally, delirium, dysphagia, immobility, and pain. Unidentified and / or untreated delirium has been shown to contribute to both morbidity and mortality in people with dementia (41); in addition, hospital transfers have been implicated in the onset or exacerbation of delirium (42). Poor knowledge of the relationship between dysphagia and advanced dementia was also identified in both caregivers and family members of people with dementia. The association between late-stage dementia, dysphagia, and aspiration pneumonia, and, further, their joint contribution to morbidity and mortality, have been identified by a number of authors (43, 44); identifying dysphagia in advanced dementia as an important indicator of disease progression and impending mortality is a critical component of related care within a palliative framework.

Study respondents also struggled to identify the relationship between advanced dementia and limited mobility. Immobility has been linked to a raft of complications that may contribute to morbidity and mortality, and it is an important consideration for those who care for people living with advanced dementia (45). Reduced mobility has been identified as a predictor of death in people 
with advanced Alzheimer's disease and vascular dementia, and it is thus useful as a prognostic indicator and an important factor in care planning and provision (46). Failure to identify reduced mobility as a symptom of advanced dementia may leave the affected individual vulnerable to related symptoms, inappropriate interventions, and increased suffering.

It has been determined that both pain and dementia are common in older adults, and they are not infrequently experienced simultaneously (47). Pain has further been shown to be poorly recognized and managed in older people, especially those with advanced dementia (48). This study's findings support these observations, showing that DKAT 2 respondents struggle to identify that pain can be assessed in persons with advanced dementia. The impact of unrelieved pain on morbidity, mortality, and quality of life in this cohort has been identified (49); for those with advanced dementia who are likely to be unable to communicate their distress effectively, awareness of the likely presence of pain is a fundamental prerequisite for responding therapeutically.

Of additional concern in all of these findings is the way in which knowledge deficits vary. While it is heartening to see that overall knowledge of dementia is associated with health professional status, our data indicate that some family members can have have better knowledge of dementia than senior RNs (Figure 1). Such unevenness in knowledge may contribute to tensions arising when staff and family members come together to make decisions with divergent understandings (50). Evidence indicates that conflict and distrust can develop when staff and family members lack confidence in each other's knowledge of dementia (51), and that this can undermine the establishment of constructive relationships between the parties (52).

Finally, it is interesting to note the relationship between aged care staff's dementia knowledge and the amount of time they have spent working in the residential aged care sector. This finding supports other research identifying the association between aged care workers' length of working life and knowledge of palliative care $(53,54)$. In Australia and elsewhere, issues related to recruitment and retention in this sector are endemic $(55,56)$, which means that the possibility of many aged care staff working long enough to accumulate better dementia knowledge is diminished; such issues also problematize a reliance on staff learning relevant information slowly, over time, across a range of aged care positions.

\section{CONCLUSION}

The findings of this study suggest that it is critical for knowledge deficits among residential aged care staff and the family members of people living with dementia to be addressed. Shared knowledge of dementia may enhance partnerships in which substantive collaborative communication and decision making can occur. Along with Kuhn, King, and Fulton (57), we recognize that decision making is a complex process and do not argue that increased knowledge will inevitably give rise to behaviours or decisions that will enhance care. However, we do contend that when family caregivers and healthcare workers share an understanding of dementia as a life-limiting health condition, it can serve as a foundation for, or mediator of, conversations about related care planning and the achievement of evidence-based outcomes. In this sense, it is essential to support any intervention to improve the provision of care for people living with dementia with a good understanding of the concerned parties' relative knowledge of dementia. This paper highlights the need to develop staff capacity to recognize dementia's clinical course, find ways to improve family and staff knowledge of the dementia trajectory, and engage in collaborative and informed care planning. In order to make appropriate care decisions that will maximize the quality of life of people living with dementia from within a palliative framework, we must first understand stakeholder capacity. This means clarifying both the strengths and the gaps in the dementia knowledge of healthcare workers and the families of those experiencing dementia.

\section{ACKNOWLEDGEMENTS}

The authors wish to acknowledge the significant contribution made to this study by its supporting funding bodies: the Department of Health of the Australian government; Wicking Dementia Research and Education Centre, University of Tasmania (UTAS); and School of Nursing and Midwifery, Faculty of Health Sciences, Curtin University. We would also like to thank the participating RACF staff and residents' family members. The Wicking Centre, a flagship of UTAS's Faculty of Health, was established in 2008 and is core-funded by the JO \& JR Wicking Trust (managed by the ANZ Trustees), with significant contributions from UTAS and the Tasmanian Department of Health and Human Services. The Wicking Centre particularly acknowledges the support of the UTAS School of Nursing and Midwifery and the UTAS School of Medicine.

The authors have no competing interests to declare, financial or otherwise.

Received: March 2, 2014

Final version accepted: June 23, 2014 


\section{REFERENCES}

1. Ferri C, Prince M, Brayne C, et al. Global prevalence of dementia: a Delphi consensus study. Lancet 2005; 366(9503): 2112-2117.

2. Deloitte Access Economics. Dementia across Australia: 20112050. Crow's Nest (NSW): Alzheimer's Australia; 2011.

3. Department of Health and Ageing (Australia). Living longer. Living better. Canberra: Department of Health and Ageing; 2012.

4. Australian Institute of Health and Welfare (AIHW). Residential aged care in Australia, 2008-2009: a statistical overview. Canberra: AlHW; 2010.

5. Productivity Commission (Australia). Trends in aged care services: some implications. Productivity Commission Research Paper. Canberra: Productivity Commission; 2008.

6. Mitchell SL, Teno JM, Kiely DK, et al. The clinical course of advanced dementia. N Engl J Med 2009; 361(16): 1529-1538.

7. Department of Health and Ageing (Australia). Guidelines for a palliative approach to residential aged care - enhanced version. Canberra: Department of Health and Ageing; 2006.

8. Department of Health and Ageing (Australia). Guidelines for a palliative approach for aged care in the community setting: best practice guidelines for the Australian context. Canberra: Department of Health and Ageing; 2011.

9. High DM, Rowles GD. Nursing home residents, families, and decision making: towards an understanding of progressive surrogacy. J Aging Stud 1995; 9(2): 101-117.

10. Andrews S, Mclnerney F, Robinson A. Realizing a palliative approach in dementia care: strategies to facilitate aged care staff engagement in evidence-based practice. Int Psychogeriatr 2009; 21(1 Suppl): S64-S68.

11. Corbett A, Husebo B, Malcangio M, et al. Assessment and treatment of pain in people with dementia. Nat Rev Neurol 2012; 8(5): 264-274.

12. Di Guilio P, Toscani F, Villani $D$, et al. Dying with advanced dementia in long-term care geriatric institutions: a retrospective study. J Palliat Med 2008; 11(7): 1023-1028.

13. Sampson E, Ritchie C, Lai R, et al. A systematic review of the scientific evidence for the efficacy of a palliative care approach in advanced dementia. Int Psychogeriatr 2005; 17(1): 31-40.

14. Spector A, Orrell M, Schepers A, et al. A systematic review of "knowledge of dementia" outcome measures. Ageing Res Rev 2012; 11(1): 67-77.

15. Finucane A, Stevenson B, Moyes R, et al. Improving end-of-life care in nursing homes: implementation and evaluation of an intervention to sustain quality of care. Palliative Med 2013; 27(8): 772-778.

16. Hughes J, Bagley $\mathrm{H}$, Reilly $\mathrm{S}$, et al. Care staff working with people with dementia: training, knowledge and confidence. Dementia 2008; 7(2): 227-238.

17. Jones C, Moyle W, Stockwell-Smith G. Caring for older people with dementia: an exploratory study of staff knowledge and perception of training in three Australian dementia care facilities. Australas J Ageing 2012; 32(1): 52-55.

18. Gilleard C, Groom F. A study of two dementia quizzes. Br J Clin Psychol 1994; 33(4 Pt): 529-534.

19. Proctor R, Martin C, Hewison J. When a little knowledge is a dangerous thing: a study of a carers' knowledge about dementia, preferred coping style and psychological distress. Int $J$ Geriatr Psychiatry 2002; 17(12): 1133-1139.

20. Graham C, Ballard C, Sham P. Carers' knowledge of dementia, their coping strategies and morbidity. Int J Geriatr Psychiatry 1997; 12(9): 931-936.

21. Stirling C, Mclnerney F, Andrews S, et al. A tool to aid talking about dementia and dying - development and evaluation. Collegian; forthcoming.

22. Toye C, Lester L, Popescu A, et al. Dementia Knowledge Assessment Tool Version Two: development of a tool to inform preparation for care planning and delivery in families and care staff. Dementia 2014; 13(2): 248-256.

23. Jorm A, Mackinnon A. The Psychogeriatric Assessment Scales. Canberra: National Health and Medical Research Council Social Psychiatry Research Unit, Mental Heath Research Institute, Australian National University; 1995.
24. Reisberg B, Ferris S, de Leon M, et al. The Global Deterioration Scale for assessment of primary degenerative dementia. Am J Psychiatry 1982; 139(9): 1136-1139.

25. Moder K. Alternatives to F-test in one way ANOVA in case of heterogeneity of variances (a simulation study). Psychol Test Assess Model 2010; 52(4): 343-353.

26. Field A. Discovering statistics using IBM SPSS Statistics. 4th ed. London: Sage; 2013.

27. Onwuegbuzie A, Daniel L. Uses and misuses of the correlation coefficient. Res Sch 2002; 9(1): 73-90.

28. King D, Mavromaras K, Wei Z, et al. The aged care workforce, 2012. Canberra: Department of Health and Ageing; 2012.

29. Nunnally JC. Psychometric theory. 2nd ed. New York: McGraw Hill; 1978.

30. Werner P. Correlates of family caregivers' knowledge about Alzheimer's disease. Int J Geriatr Psychiatry 2001; 16(1): 3238.

31. Connell CM, Roberts S, McLaughlin S. Public opinion about Alzheimer disease among blacks, hispanics and whites: results from a national survey. Alzheimer Dis Assoc Disord 2007; 21(3): 232-240.

32. Werner P. Lay perceptions about mental health: where is age and where is Alzheimer's disease? Int Psychogeriatr 2005; 17(3): 371-382.

33. Hansen EC, Hughes C, Routley G, et al. General practitioners' experiences and understandings of diagnosing dementia: factors impacting on early diagnosis. Soc Sci Med 2008; 67(11): 1776-1783.

34. Turner S, lliffe S, Downs M, et al. General practitioners' knowledge, confidence and attitudes in the diagnosis and management of dementia. Age Ageing 2004; 33(5): 461-467.

35. Johnson A, Chang E, Daly J, et al. The communication challenges faced in adopting a palliative care approach in advanced dementia. Int J Nurs Pract 2009; 15(5): 467-474.

36. Bryans M, Keady J, Turner S, et al. An exploratory survey into primary care nurses and dementia care. Br J Nurs 2003; 12(17): 1029-1037.

37. Australian Institute of Health and Welfare (AlHW). Dementia in Australia. Canberra: AlHW; 2012.

38. Birch D, Draper J. A critical literature review exploring the challenges of delivering effective palliative care to older people with dementia. J Clin Nurs 2008; 17(9): 1144-1163.

39. Chang E, Hancock K, Harrison K, et al. Palliative care for endstage dementia: a discussion of the implications for education of health care professionals. Nurse Educ Today 2005; 25(4): 326-332.

40. World Health Organization (WHO). Dementia: a public health priority. Geneva: WHO; 2012.

41. Leslie DL, Zhang Y, Bogardus ST, et al. Consequences of preventing delirium in hospitalized older adults on nursing home costs. J Am Geriatr Soc 2005; 53(3): 405-409.

42. Fick DM, Agostini JV, Inouye SK. Delirium superimposed on dementia: a systematic review. J Am Geriatr Soc 2002; 50(10): 1723-1732.

43. Miller N, Carding P. Dysphagia: implications for older people. Rev Clin Gerontol 2007; 17(3): 177-190.

44. Cabre M, Serra-Prat M, Palomera E, et al. Prevalence and prognostic implications of dysphagia in elderly patients with pneumonia. Age Ageing 2010; 39(1): 39-45.

45. Campbell ML, Guzman JA. A proactive approach to improve end-of-life care in a medical intensive care unit for patients with terminal dementia. Crit Care Med 2004; 32(9): 1839-1843.

46. Koutsavlis AT, Wolfson C. Elements of mobility as predictors of survival in elderly patients with dementia: findings from the Canadian Study of Health and Aging. Chronic Dis Can 2000; 21(3): 93-103.

47. Belin C, Gatt MT. Douleur et démence. Psychol Neuropsychiatr Vieil 2006; 4(4): 247-254

48. Zwakhalen SM, Hamers JP, Abu-Saad HH, et al. Pain in elderly people with severe dementia: a systematic review of behavioural pain assessment tools. BMC Geriatr 2006; 6: 3.

49. Snow L, Rapp MP, Kunik M. Pain management in persons with dementia. BODIES mnemonic helps caregivers relay painrelated signs, symptoms to physicians and nursing staff. Geriatrics 2005; 60(5): 22-25. 
50. Bauer M, Nay R. Improving family-staff relationships in assisted living facilities: the views of family. J Adv Nurs 2011; 67(6): 1232-1241.

51. Pashby P, Hanna J, Sunico ME. Dementia care planning: shared experience and collaboration. J Gerontol Soc Work 2009; 52(8): 837-848.

52. Bauer M, Fetherstonhaugh D, Tarzia L, et al. Staff-family relationships in residential aged care facilities: the views of residents' family members and care staff. J Appl Gerontol 2014; 33(5): 564-585.

53. Proctor R, Grealish L, Coates M, et al. Nurses' knowledge of palliative care in the Australian Capital Territory. Int J Palliat Nurs 2000; 6(9): 421-428.
54. Ford R, Mclnerney F. An evaluation of aged-care workers' knowledge of and attitudes toward the palliative approach. Res Gerontrol Nurs 2011; 4(4): 251-259.

55. Howe AL, King DS, Ellis JM, et al. Stabilising the aged care workforce: an analysis of worker retention and intention. Aust Health Rev 2012; 36(1): 83-91.

56. Elliott KJ, Scott JL, Stirling C, et al. Perspectives of the community-based dementia care workforce: "occupational communion" a key finding from the Work 4 Dementia Project. Int Psychogeriatr 2013; 25(5): 765-774.

57. Kuhn D, King SP, Fulton BR. Development of the Knowledge about Memory Loss and Care (KAML-C) test. Am J Alzheimer Dis Other Demen 2005; 20(1): 41-49. 